\title{
Studi Kasus : Kesiapan Rumah Sakit An - Nisa Tangerang Dalam Implementasi Program Jaminan Kesehatan Nasional
}

\section{CASE STUDY : READINESS OF AN - NISA HOSPITAL TANGERANG IN THE IMPLEMENTATION OF THE NATIONAL HEALTH INSURANCE PROGRAM}

\author{
Luh Putu Sinthya Ulandari ${ }^{1^{*}}$, dan Yaslis Ilyas ${ }^{2}$ \\ ${ }^{1}$ Program Studi Kesehatan Masyarakat, Fakultas Kedokteran, Universitas Udayana \\ J1. P.B. Sudirman, Denpasar Indonesia \\ ${ }^{2}$ Fakultas Kesehatan Masyarakat, Universitas Indonesia \\ *Email : sinthyaulandari@yahoo.com
}

Submitted:05-03-2019, Revised: 12-06-2019, Revised: 12-9-2019, Accepted : 27-11-2019

\begin{abstract}
Health facilities play an important role in achieving the goals of National Health Insurance $(J K N)$, to providing health services to all Indonesian people. The study aimed to determine the readiness of An - Nisa Hospital as one of the private hospitals in Tangerang in the implementation of the JKN. This research was conducted in March 2018 using a qualitative approach through in-depth interviews and documentation study. The sample was determined purposively, consisting of 7 internal informants from An - Nisa Hospital. Data were analyzed using thematic analysis. Various preparations have been made by An - Nisa Hospital before the hospital joined the BPJS Kesehatan provider, starting from casemix training, coding, costing, preparing clinical pathways, and learning about an information technology systems used in the JKN era. The addition of human resources, facilities and infrastructure was also carried out to support the implementation of JKN. An - Nisa Hospital formed a casemix team whose task was to compile claim documents and collect claims to BPJS Kesehatan. This study concludes that An - Nisa Hospital had prepared themselves before joining the BPJS Kesehatan provider, and the hospital is fully committed to successful the JKN Program.
\end{abstract}

Keywords: preparation, implementation, national health insurance

\begin{abstract}
Abstrak
Fasilitas kesehatan memegang peranan penting dalam tercapainya tujuan Jaminan Kesehatan Nasional (JKN) yaitu dalam memberikan pelayanan kesehatan kepada seluruh masyarakat Indonesia. Tujuan dari penelitian ini adalah untuk mengetahui kesiapan dari RS An - Nisa sebagai salah satu rumah sakit swasta di Tangerang dalam implementasi Program JKN. Penelitian dilakukan pada Maret 2018 dengan pendekatan kualitatif. Data dikumpulkan dengan wawancara mendalam dan studi dokumen. Sampel ditentukan secara purposive, yang terdiri dari 7 informan pihak internal RS An - Nisa. Data dianalisis secara deskriptif kualitatif. Berbagai persiapan telah dilakukan oleh RS An - Nisa sebelum mereka bergabung menjadi provider BPJS Kesehatan, mulai dari mengikuti pelatihan casemix, coding, costing, penyusunan clinical pathway, serta menikuti pembelajaran tentang sistem informasi teknologi yang digunakan di era JKN. Penambahan SDM, fasilitas sarana dan prasarana pun dilakukan guna mendukung penyelenggaraan JKN. RS An - Nisa membentuk sebuah tim casemix yang bertugas untuk menyusun dokumen klaim dan melakukan penagihan klaim kepada BPJS Kesehatan. Penelitian ini menyimpulkan bahwa RS An - Nisa telah mempersiapkan diri secara totalitas sebelum bergabung menjadi provider BPJS Kesehatan, serta berkomitmen penuh dalam menyukseskan program JKN.
\end{abstract}

Kata kunci: Persiapan, implementasi, jaminan kesehatan nasional 


\section{PENDAHULUAN}

Program Jaminan Kesehatan Nasional (JKN) telah berjalan selama 5 tahun dalam memberikan jaminan perlindungan pelayanan kesehatan dasar kepada seluruh masyarakat Indonesia. Setiap tahunnya jumlah peserta JKN mengalami peningkatan yang signifikan. Terhitung pada September 2018, jumlah peserta JKN telah mencapai 202.160.855 jiwa. ${ }^{1}$ Peningkatan jumlah peserta JKN setiap tahunnya perlu didukung dengan penambahan jumlah fasilitas kesehatan (faskes) baik pada tingkat FKTP maupun pada tingkat FKTL agar peserta JKN dapat terlayani.

Salah satu upaya pemerintah dalam menjamin ketersediaan faskes dalam melayani peserta JKN adalah dengan mengeluarkan Perpres No.19 Tahun 2016 yang menghimbau kepada seluruh faskes milik pemerintah dan pemerintah daerah yang telah memenuhi persyaratan untuk wajib bekerja sama dengan BPJS Kesehatan. ${ }^{2}$ Untuk faskes milik swasta tidak diwajibkan bermitra dengan BPJS Kesehatan, namun mereka dapat menjadi provider apabila bersedia dan telah memenuhi persyaratan yang ditetapkan. Peran faskes swasta terutama pada tingkat lanjutan perlu dipetimbangkan, mengingat jumlah peserta JKN bertambah setiap tahun. Pemerintah dan BPJS Kesehatan harus mendorong pertumbuhan peran swasta sebagai salah satu penyelenggara pelayanan kesehatan di era JKN.

Sampai saat ini, di beberapa daerah masih terdapat beberapa rumah sakit swasta yang belum bermitra dengan BPJS Kesehatan karena beberapa isu, diantaranya: tarif INA-CBG's yang dirasakan masih rendah dan terlambatnya pembayaran klaim oleh BPJS Kesehatan sehingga mengakibatkan terganggunya cash flow beberapa rumah sakit. Berbagai kendala masih dihadapi oleh pihak RS, seperti: kurangnya SDM yang berkompeten dalam penyusunan dokumen klaim, sistem informasi teknologi yang kurang mendukung, rendahnya pengetahuan dan kemampuan SDM dalam memasukkan data klaim ke dalam sistem IT, serta pemahaman SDM akan code INA-CBG's yang masih rendah. Sejalan dengan penelitian Rahman et al, yang menyatakan bahwa implementasi kebijakan JKN di RSUD Undata Palu belum maksimal, seperti: komunikasi yang kurang baik antara petugas dan pasien, dan perlu dilakukan penambahan SDM mengingat meningkatnya jumlah kunjungan pasien. ${ }^{3}$

Untuk keberlangsungan Program JKN, maka perlu dilakukan perbaikan secara berkala terhadap faskes baik pada tingkat FKTP maupun FKTL selaku penyelenggara pelayanan kesehatan. Persiapan yang matang sangat dibutuhkan terutama bagi faskes tingkat lanjut milik swasta yang akan bergabung menjadi provider BPJS Kesehatan, agar dapat mengimplementasikan JKN secara baik. Persiapan yang matang tidak cukup untuk menjamin terlaksananya pelaksanaan JKN dengan baik pada instansi pelayanan kesehatan, tetapi dibutuhkan komitmen yang tinggi dalam penerapannya.

Rumah sakit An-Nisa merupakan salah satu rumah sakit swasta di Tangerang yang telah memperoleh apresiasi dari pemerintah pada tahun 2014 dan 2017 sebagai rumah sakit yang paling berkomitmen dalam pelaksanaan JKN. Berdasarkan studi pendahuluan, diperoleh informasi bahwa Rumah Sakit An-Nisa telah bergabung menjadi provider BPJS Kesehatan sejak 1 Januari 2014. Ada beberapa hal yang melatarbelakangi RS An-Nisa memutuskan untuk bermitra dengan BPJS Kesehatan, diantaranya: Kesatu. RS An-Nisa telah bekerjasama sebelumnya dengan Jamsostek dan saat itu mereka mampu dalam mengelola pasien Jamsostek dengan baik. Kedua. Adanya komitmen dari RS An-Nisa dalam mendukung dan menyukseskan program Pemerintah Indonesia. Hadirnya program JKN dijadikan peluang oleh rumah sakit, mengingat pada tahun 2019 seluruh penduduk Indonesia wajib bergabung ke dalam program JKN. Kondisi ini merupakan pasar yang sangat besar jika mampu mengelola pasien JKN dengan baik.

Untuk dapat mengimplementasikan Program JKN dengan baik, maka sangat diperlukan kesiapan yang matang oleh pihak RS An-Nisa Tangerang. Sehubungan dengan hal tersebut, maka tujuan penelitian ini adalah mengetahui persiapan dan kesiapan dari RS AnNisa Tangerang dalam pelaksanaan Program Jaminan Kesehatan Nasional. 


\section{BAHAN DAN METODE}

Penelitian ini dilakukan di RS An-Nisa Tangerang pada bulan Maret - Juni 2018, dengan pendekatan kualitatif. Data dikumpulkan melalui wawancara mendalam kepada 7 orang informan yaitu Direktur Utama PT. An-Nisa, direktur RS An-Nisa, manajer keuangan, manajer SDM dan umum, manajer resiko, supervisor humas internal, dan kepala bagian tim casemix yang dipilih dengan metode purposive dan data dianalisis dengan teknik analisis tematik. Untuk validitas data penelitian dilakukan triangulasi sumber dan triangulasi metode.

\section{HASIL}

Program JKN diluncurkan pada 1 Januari 2014, namun sebelumnya An-Nisa telah menyusun berbagai upaya persiapan untuk bergabung menjadi provider BPJS Kesehatan. Pada bulan Maret 2013, beberapa pihak internal RS mengikuti pelatihan dan pembelajaran selama 20 hari dengan 10 modul dan 5 topik yang berkaitan dengan konsep casemix, coding, cara menghitung costing, mekanisme pumbuatan clinical pathway dan pentingnya IT.

"....kami mulai menyiapkan diri sejak bulan Maret 2013. Jadi An-Nisa sudah belajar langsung ke gurunya.. konsultan kita, konsultan Indonesia kebetulan orang Malaysia Prof. Syed Aljunid, kami belajar selama 20 hari.. 10 modul, 5 topik, yaitu: apa itu konsep casemix, bagaimana membuat koding, bagaimana menghitung costingnya, bagaimana membuat clinical pathway, dan pentingnya IT. Jadi kami belajar 5 topik itu selama 20 hari. Jadi An-Nisa menyiapkan diri 8 bulan sebelum program itu dijalankan dengan biaya yang cukup besar" (IN1).

Tidak hanya mengikuti pelatihan, sosialisasi pun gencar dilakukan kepada seluruh staff di RS, tidak hanya pada level koordinator atau supervisor agar mereka memahami bagaimana mekanisme pelaksanaan JKN serta menerapkan prinsip kendali mutu dan biaya dalam pelaksanaannya.

"Jadi mulai dari disini pelatihanpelatihan internal yang terkait dengan program
JKN itu sendiri... casemix, codingnya seperti apa.. itu harus selalu disosialisasikan ke seluruh karyawan.. bagaimana caranya kita bisa efisiensi dengan sistem paket seperti BPJS Kesehatan ini. Jadi bukan cuma di level yang mungkin tingkatnya coordinator atau supervisor, tapi keseluruh karyawan pun kita menerapkan bagaimana kita menjadi efisien, gitu kan" (IN4).

Persiapan lain yang dilakukan oleh pihak internal RS adalah membentuk unit baru, yaitu tim casemix yang betugas untuk menyiapkan berkas atau dokumen klaim yang akan diajukan ke BPJS Kesehatan, serta memastikan bahwa berkas klaim yang diajukan telah memenuhi persyaratan sehingga kelancaran pembayaran klaim akan terjamin. Struktur organisasi juga mengalami perubahan, dari struktur organisasi fungsional menjadi struktur organisasi matriks. Perubahan struktur organisasi menjadi matriks sangat membantu di era JKN ini, karena dengan struktur organisasi matriks memungkinkan untuk merespon beberapa sektor lingkungan secara serentak, dan mampu mengintegrasikan semua bagian yang ada.

"ada.. kalau yang terakhir kan matriks, kalau dulu sebelumnya kan struktur biasa. Jadi kalau sekarang itu saling mempertemukan antara kami yang di manajerial, yang fungsional sama yang di ka.instalasi.. yang jagain. Jadi Ka'ins itu yang jagain semuanya, dari hulu ke hilir.." (IN-3).

"di tahun 2015... sebelumnya kami pakai fungsional berubah menjadi matrix.. struktur organisasi matrix yang kami pakai. Dan itu ternyata sangat membantu pada saat kita harus mengawal JKN" (IN-1).

Berbeda dengan stuktur organisasi fungsional, terkadang sulit untuk mengontrol organisasi karena banyaknya bidang yang terlalu fokus pada fungsinya masing - masing sehingga perlu merekrut dewan pengawas di setiap bidang.

"....kalau organisasi fungsional kita terpaku pada fungsi - fungsi.. ada fungsi medis, fungsi keperawatan, fungsi penunjang, fungsi SDM, fungsi keuangan.. kita tidak terlalu berorientasi pada produknya.. pada jenis layanannya" (IN-1).

Sehubungan dengan kebijakan yang 
mendukung implementasi Program JKN, berdasarkan hasil penelitian diperoleh bahwa ada beberapa kebijakan RS, diantaranya: tidak adanya pembatasan kuota/ tempat tidur, tidak menarik iuran biaya kepada peserta JKN, tidak membatasi pelayanan kesehatan, tidak ada diskriminasi, memberikan kemudahan bagi peserta JKN untuk mengaskes pelayanan serta kebijakan kendali mutu dan kendali biaya. Untuk kendali mutu dilakukan dengan mengacu pada standar akreditasi rumah sakit sedangkan untuk kendali biaya dilakukan dengan mencari dan membeli barang - barang dengan harga murah tanpa mengabaikan kualitas.

"Jadi kebijakannya adalah kita menerima pasien JKN tanpa selisih biaya, tidak ada pembatasan kuota.. jadi kalau misalnya pasien datang di jam pelayanan.. kita kan dokter juga gak ada pembatasan kan dari jam sekian pasien BPJS... jam sekian pasien umum.. enggak !" (IN-7).

"Jadi itu yang membuat, oke tetep dengan standar, dengan standar yang kita ambil adalah standar akredetasi rumah sakit. Kendali biaya kita terutama pada harga pokok pembelian" (IN-5).

Kebijakan lain yang dibuat untuk mendukung pelaksanaan program JKN adalah memperbanyak kelas perawatan khususnya kelas 2, dilanjutkan dengan kelas 1 dan kelas 3. Untuk saat ini VIP yang tersedia di RS An - Nisa tidak banyak, hanya terdapat 3 kelas VIP. Sehubungan dengan sistem teknologi informasi, persiapan yang dilakukan adalah mematikan sistem IT yang lama dan menggantinya dengan sistem IT yang baru, yaitu: Indonesian Clinic \& Hospital Asset (ICHA) agar dapat dilakukan bridging system dengan BPJS Kesehatan.

Untuk pelaksanaan JKN, RS An - Nisa melakukan penambahan tempat tidur (TT), dimana pada awalnya jumlah TT hanya sekitar 120 TT dan saat ini sudah bertambah menjadi 170 TT. Tingginya kunjungan pasien yang ingin berobat ke RS An-Nisa membuat RS An-Nisa harus segera meningkatkan jumlah TT, dimana saat ini target RS adalah memiliki 200 TT dengan 5 kamar operasi.

"tempat tidur kami 170 sekarang itu kurang, kamar operasi kami itu kurang karena market begitu banyak yang ingin berobat ke AnNisa, makanya kami sekarang meningkatkan tempat tidur lagi sebanyak 30. Jadi targetnya AnNisa 200 tempat tidur dengan 5 kamar operasi" (IN - 1).

Penambahan SDM pun dilakukan untuk mendukung implementasi program JKN. Pada saat mengimplementasikan Program JKN, RS An - Nisa melakukan penambahan SDM yang cukup banyak terutama pada unit produksi yaitu dokter, perawat dan petugas penunjang medis. Pihak RS An - Nisa melakukan penambahan untuk tenaga perawat dan tenaga medis yang sebelumnya hanya berjumlah sekitar 250 tenaga dan saat ini jumlah sudah mencapai sekitar 424 tenaga.

"Ya terjadi penambahan SDM pasti.. gini, yang pertama kali itu karena kapasitas kita naik pasti yang naik itu unit produksi, contoh: dokter, dokter umum pasti nambah, keperawatan pasti nambah banyak... petugas-petugas penunjang lab, radiologi, apotik itu pasti berubah, gitu” (IN-3).

Sehubungan dengan kendali mutu dan kendali dalam implementasi JKN, RS AnNisa telah menyusun formularium dan clinical pathway. Penyusunan formularium telah mengacu pada formularium nasional (fornas), dimana penyusunan ini melibatkan tim farmako - terapi RS An-Nisa.

Kesiapan dalam implementasi JKN tidak hanya dilihat dari adanya penambahan SDM atau sarana dan prasarana, tetapi kesiapan pemimpin juga perlu dipertimbangkan mengingat pemimpin merupakan hal yang penting dalam keberlangsungan suatu organisasi atau perusahaan. Direktur RS An-Nisa menerapkan gaya kepemimpinan transformatif dalam memimpin RS An-Nisa. Direktur RS An-Nisa memposisikan dirinya sebagai mentor yang lebih banyak menghabiskan waktu untuk berdiskusi kepada para staff untuk memberikan solusi atas segala permasalahan yang dihadapi dalam pelaksanaan operasional.

"Iya, saya itu menganut gaya kepemimpinan yang transformative. Jadi bagaimana kita sama - sama bisa berubah ya kan.. yang dari tadinya tidak mampu menjadi mampu. Untuk itu saya memposisikan diri 
sebagai mentor bagi mereka. Jadi mereka silahkan datang ke saya, membawa masalahnya.. saya pelajari, saya carikan solusi habis itu kita berdiskusi, disitulah proses transfer knowledge saya." (IN-1).

Dalam menjalankan dan memimpin rumah sakit ini, pemimpin selalu melakukan pengawasan (control) dan melakukan pemberdayaan (empowerment). Pengawasan dilakukan agar seluruh karyawan/staff menjalankan kebijakan yang ada dan memastikan agar proses bisnis berjalan secara efisien. Sedangkan pemberdayaan dilakukan dengan menggali dan mengembangkan potensi yang mereka miliki melalui pemberian pelatihan, seminar, dan kesempatan untuk melanjutkan pendidikan mereka serta memberikan mereka motivasi seperti dengan pemberian reward seperti bonus dan sebagainya.

Dalam implementasi JKN, kesiapan lain yang perlu diperhatikan adalah siap bekerja sama atau berkolaborasi antar bagian atau divisi yang ada. Untuk membangun hal tersebut, RS An-Nisa menerapkan transparansi dan rasa kepercayaan (trust). Kesiapan dari sisi komunikasi, untuk memastikan bahwa setiap staff memperoleh informasi JKN terbaru, maka pihak RS An-Nisa melakukan rapat manajemen yang dilakukan seminggu sekali antara manajer dan direktur, rapat koordinasi dilakukan setiap satu bulan sekali yang melibatkan semua kepala bidang, koordinator dan direktur, serta membuat group whats up untuk media komunikasi sehari - hari.

\section{PEMBAHASAN}

Rumah Sakit An - Nisa Tangerang memutuskan bermitra dengan BPJS Kesehatan sejak 1 Januari 2014. Salah satu latar belakang RS An-Nisa menjadi provider BPJS Kesehatan adalah ingin mendukung dan menyukseskan program JKN dalam rangka memberikan jaminan pelayanan kesehatan kepada seluruh peserta JKN. Bergabungnya fasilitas kesehatan tingkat lanjut milik swasta tentunya sangat diharapkan oleh pemerintah guna memberi keseimbangan antara demand dan supply terhadap pelayanan kesehatan. ${ }^{5}$ Berbagai persiapan telah dilakukan oleh RS An-Nisa dalam mengimplementasikan program JKN, seperti mengikuti pembelajaran dan pelatihan terkait dengan casemix, coding, costing, pembuatan clinical pathway, dan pengembangan IT. Hal tersebut memang perlu dikuasai dengan baik terutama bagi FKTL yang ingin bermitra dengan BPJS Kesehatan, karena kendala dalam implementasi JKN diantaranya adalah ketidakmampuan SDM dalam menguasai coding dan kurangnya keterampilan serta kemampuan dalam mengoperasikan atau menggunakan sistem IT JKN. Hal tersebut senada dengan penelitian Mardiawati et al, yang menunjukkan bahwa pengkodean dengan sistem komputerisasi belum berjalan maksimal karena petugas koding yang masih baru sehingga diperlukan penguatan SDM melalui pemberian pelatihan dan peningkatan keterampilan. ${ }^{6}$ Hasil penelitian Putra juga menunjukkan bahwa kendala dalam implementasi JKN di RSU Kota Tangerang Selatan salah satunya adalah sistem IT, dimana sistem IT JKN yang digunakan sering mengalami gangguan sehingga menghambat proses pelayanan pendaftaran, pembuatan surat eligibilitas peserta JKN dan memperlambat proses pemberkasan klaim. ${ }^{7}$

RS An-Nisa juga melakukan pembentukan tim casemix dalam persiapan implementasi JKN. Ini merupakan salah satu upaya yang dilakukan RS An-Nisa dalam mewujudkan proses manajemen klaim agar dapat berjalan dengan baik. Hasil penelitian Mahmudah et al, diperoleh bahwa RSI Sultan Agung juga membentuk tim JKN, dimana Tim JKN ini bertugas untuk merencanakan, mengawasi, mengontrol, dan mengevaluasi jalannya pelaksanaan program JKN di RSI Sultan Agung. ${ }^{5}$

Ketersediaan SDM dalam pelaksanaan pelayanan kesehatan memegang peranan penting dan perlu dipertimbangan baik dari sisi kuantitas dan kualitasnya di era JKN ini. Pihak RS AnNisa melakukan banyak penambahan pada tenaga - tenaga yang berada di unit produksi, seperti misalnya dokter, dokter spesialis, perawat, rekam medis dan penunjang medis lainnya. Penambahan jumlah SDM di unit produksi memang penting dilakukan mengingat ke depannya jumlah peserta dan pasien yang dilayani akan meningkat. Senada dengan hasil penelitian Mahmudah et al, yang menunjukkan bahwa 
RSI Sultan Agung Semarang juga melakukan penambahan SDM untuk menyambut penerapan program JKN, diantaranya: penambahan petugas administrasi dan penambahan tenaga medis yang terdiri dari perawat dan dokter untuk mendukung pembukaan bangsal VIP dan VVIP. ${ }^{5}$ Kecukupan jumlah SDM sangat diperlukan untuk menjamin pemberian pelayanan kesehatan yang maksimal. Terkait dengan sarana dan prasarana, upaya yang dilakukan rumah sakit adalah dengan menambah jumlah tempat tidur, menambah jumlah ruang perawatan terutama untuk kelas 2, dilanjutkan kelas 1 dan kelas 3 dengan mengurangi jumlah VIP yang ada di rumah sakit, serta melengkapi alat diagsnotik. Sejauh ini, dukungan sarana dan prasarana di RS An-Nisa telah memenuhi standar RS tipe C. Senada dengan hasil penelitian Mahmudah et al, menunjukan bahwa persiapan yang dilakukan RSI Sultan Agung dalam menyambut implementasi JKN adalah merelokasi ruang perawatan kelas 1 dan kelas 2 dengan cara merubah ruang perawatan VIP yang tidak sesuai standar menjadi kelas 1, dan merubah ruang perawatan kelas 1 menjadi kelas 2 , sedangkan untuk ruang perawatan kelas 3 tidak dilakukan penambahan ruangan. ${ }^{5}$

Sehubungan dengan sistem aplikasi, saat ini RS An- Nisa menggunakan aplikasi V-klaim, aplikasi INA-CBG's dan aplikasi internal RS yang disebut ICHA. RS An-Nisa telah mengembangkan bridging system antara aplikasi ICHA dengan V-klaim dan aplikasi INA - CBG's. Tujuan dilakukannya bridging system ini adalah untuk efisiensi penggunaan sumber daya, untuk meningkatkan efektivitas dalam proses entry data, serta mempermudah dan mempercepat proses verifikasi dan pengelolaan klaim. Hal tersebut senada dengan pendapat Mahmudah et al, yang menyatakan bahwa bridging system yang dilakukan antara aplikasi RS dengan aplikasi BPJS Kesehatan dapat meningkatkan layanan administrasi, penghematan tenaga SDM serta membuat proses pengajuan klaim menjadi lebih cepat. ${ }^{5}$

Terkait dengan kendali mutu dan kendali biaya di era JKN ini, upaya yang dilakukan pihak RS An-Nisa tangerang adalah dengan membuat clinical pathway dan formularium obat yang mengacu pada formularium nasional. Dengan diterapkannya clinical pathway yang biayanya mengacu pada tarif INA-CBG's dan menggunakan formularium yang mengacu pada formularium nasional, maka dapat dipastikan rumah sakit akan memperoleh keuntungan tanpa mengabaikan mutu pelayanan kesehatan. Senada dengan penelitian Mahmudah et al, yang menunjukkan bahwa upaya yang dilakukan RSI Sultan Agung untuk kendali mutu dan biaya adalah dengan berpedoman pada clinical pathway yang telah dibuat oleh pihak RS. ${ }^{5}$

Dalam sebuah organisasi, kepemimpinan memainkan perananyangpenting. Kepemimpinan dan pemimpin merupakan suatu kesatuan yang tidak dapat dipisahkan. Menurut Jack Welch dalam Pramudyo, dijelaskan bahwa pemimpin adalah seseorang yang mampu menggerakkan sumber daya yang ada dan memberikan inspirasi dengan visi dan misi yang jelas tentang bagaimana bekerja bersama untuk mencapai tujuan. ${ }^{8}$ Sedangkan kepemimpinan adalah kemampuan yang dimiliki seseorang untuk mempengaruhi suatu kelompok dalam mencapai tujuan. ${ }^{8}$ Gaya kepemimpinan yang diterapkan oleh Direktur RS An-Nisa adalah gaya kepemimpinan transformatif. Kepemimpinan transformatif didefinisikan sebagai kepemimpinan dimana pemimpin menggunakan karisma yang mereka miliki untuk melakukan transformasi dan merevitalisasi organisasinya. ${ }^{9}$

Direktur RS An-Nisa lebih memposisikan dirinya sebagai mentor dibandingkan hanya memberikan instruksi - instruksi yang bersifat top down. Hal tersebut senada dengan pendapat Hakim yang menyatakan bahwa pemimpin yang transformatiflebih memposisikan dirinya sebagai mentor yang bersedia untuk menampung segala aspirasi bawahannya dan pemimpin transformatif menekankan pada bagaimana merevitalisasi organisasinya. ${ }^{9}$

Menciptakan kolaborasi dalam suatu organisasi merupakan hal yang penting untuk dilakukan demi kelancaran proses operasi. Kolaborasi adalah suatu hubungan kerjasama yang dilakukan oleh pihak - pihak yang memiliki tujuan yang sama, persepsi yang sama, adanya kejujuran dan saling memberikan manfaat. ${ }^{10}$ 
Strategi yang dilakukan pemimpin RS AnNisa dalam membangun hubungan kerja sama/ kolaborasi adalah dengan kejujuran (trust) dan transparansi. Dengan adanya kejujuran dan transparansi, maka seluruh karyawan/staf akan menerima dan menjalankan segala kebijakan atau keputusan yang telah ditetapkan, karena mereka memiliki kepercayaan bahwa pemimpin mereka telah mempertimbangkan keputusan/kebijakan tersebut dari segala sisi, sehingga secara otomatis kerja sama/kolaborasi tersebut akan tercipta.

Komunikasi merupakan salah satu hal yang sangat erat dalam kehidupan kita sehari hari. Komunikasi dalam organisasi merupakan komunikasitimbalbalik demikepentinganseluruh pihak. Komunikasi dalam organisasi menjadi titik sentral untuk menciptakan lingkungan yang kondusif, meningkatkan kepercayaan publik, meningkatkan citra organisasi bahkan untuk mempromosikan suatu produk/jasa. ${ }^{11}$ Demi keberlangsungan organisasi dalam mencapai kesamaan makna dan tujuan yang telah ditetapkan, maka kemampuan berkomunikasi sangatlah penting, bahkan menjadi tuntutan. Sejauh ini, komunikasi yang berlangsung di RS An-Nisa sangatlah fleksibel, dimana komunikasi sehari hari dilakukan secara langsung dan melalui media Whatsapp, sedangkan untuk komunikasi secara formal dilakukan melalui rapat rutin. Rapat atau pertemuan rutin di tingkat manajerial dilakukan setiap seminggu sekali, untuk mendiskusikan masalah yang ada atau melaporkan hasil kinerjanya selama seminggu. Untuk rapat tingkat koordinasi dijadwalkan setiap bulan sekali, namun pelaksanaanya terkadang melebihi dari yang dijadwalkan. Komunikasi antara pihak RS dengan pihak BPJS Kesehatan juga diakukan melalui aplikasi whatapp group, telfon dan mengadakan pertemuan jika dibutuhkan.

Di era globalisasi dengan perkembangan teknologi komunikasi yang semakin canggih membuat masyarakat bergerak ke arah perubahan komunikasi yang mengglobal. Hal tersebut senada dengan Herawati, yang menyatakan bahwa teknologi komunikasi informasi yang saat ini berkembang membawa manusia ke dalam dunia tanpa batas. ${ }^{12}$ Sejauh ini, komunikasi yang berlangsung di RS An-Nisa berjalan dengan baik dan tidak ditemukannya kendala yang signifikan hingga menghambat jalannya kegiatan rumah sakit.

Dari berbagai upaya yang telah dilakukan oleh RS An-Nisa dapat dilihat bahwa RS AnNisa telah siap dalam mengimplementasikan Program JKN, mengingat persiapan yang telah mereka lakukan sejak Maret 2013 sebelum diluncurkannya secara resmi Program JKN.

\section{KESIMPULAN}

Penelitian ini menyimpulkan bahwa RS An-Nisa dalam pelaksanaan Program Jaminan Kesehatan sudah terlihat kesiapannya, dimulai dari penambahan jumlah SDM terutama pada unit produksi, penambahan sarana dan prasarana (seperti: ruang perawatan, jumlah tempat tidur, dan alat penunjang diagnostik lainnya), pengembangan sistem informasi teknologi, bridriging system antara SIM RS dengan aplikasi dari BPJS Kesehatan maupun aplikasi dari Kemenkes, membentuk tim casemix, serta penyusunan formularium dan clinical pathway sebagai salah satu upaya kendali mutu dan biaya.

Peningkatan tidak hanya dilakukan dari sisi jumlah, tetapi juga dari sisi kualitasnya, seperti: peningkatan kapabilitas SDM melalui pelatihan dan pembelajaran tentang costing, coding, casemix, dan penggunaan sistem IT di era JKN. Sosialisasi tentang JKN aktif dilakukan agar SDM paham mekanisme pelaksanaan program JKN dan menerapkan prinsip efisiensi dalam pelaksanaannya.

\section{UCAPAN TERIMA KASIH}

Pelaksanaan penelitian ini tidak terlepas dari berbagai hambatan, namun berkat kerjasama dan bantuan dari berbagai pihak akhirnya penelitian ini dapat diselesaikan. Kami mengucapkan terima kasih kepada seluruh informan dan pimpinan RS An-Nisa atas izin dan kesediaannya berpartisipasi dalam menyukseskan pelaksanaan penelitian ini.

Dengan segala kerendahan hati, semoga hasil penelitian ini dapat bermanfaat bagi pihak - pihak yang membutuhkan. 


\section{DAFTAR RUJUKAN}

1. BPJS Kesehatan. Capai 99\%, Kolektabilitas Iuran JKN-KIS Terus Didongkrak [Internet]. [cited 2019 Mar 1]. Available from: https:// bpjs-kesehatan.go.id/bpjs/arsip/detail/1066.

2. Kemenkumham. Peraturan Presiden Republik Indonesia Nomor 19 Tahun 2016 Tentang Perubahan Kedua Atas Peraturan Presiden Nomor 12 Tahun 2013 Tentang Jaminan Kesehatan [Internet]. 2016. [cited 2019 Mar 4]. Available from: https://djsn. go.id/storage/app/uploads/public/58c/934/ a2d/58c934a2d1d9d579396786.pdf.

3. Salim A, Hermiyanti, Rahman A. Analisis Implementasi Kebijakan Jaminan Kesehatan Nasional (JKN) di Rumah Sakit Umum Daerah (RSUD) Undata Palu. J Kesehat Tadalako. 2017;3(1):102-10.

4. Maguire M, Delahunt B. Doing a Thematic Analysis: A Practical, Step-by-Step Guide for Learning and Teaching Scholars. All Irel J Teach Learn High Educ. 2017;8(3):3135-40.

5. Mahmudah $\mathrm{P}$, Chirwardani, Wigati PA. Analisis Upaya RS Islam Sultan Agung Kota Semarang Sebagai FKTL Dalam Penerapan Program JKN Tahun 2014. J Kesehat Masyarakat2. 2015;3(1):57-64.
6. Mardiawati D, Leonard D. Analisis Pelaksanaan Pengodean Tindakan Medis Pasien JKN Di RSI Siti Rahmah Padang. J Endur. 2018;3(3):624.

7. Putra WM. Analisis Implementasi Kebijakan Jaminan Kesehatan Nasional di Rumah sakit Umum kota Tangetang Selatan. Skripsi. Universitas Islam Negeri Syarif Hidayatullah. Jakarta. 2014. 1-185 p.

8. Pramudyo A. Implementasi Manajemen Kepemimpinan. JBMA. 2013;I(2):49-61.

9. Hakim AU. Kepemimpinan Transformatif [Internet]. Kompasiana. 2011 [cited 2019 Mar 5]. Available from: https://www.kompasiana. com/audiendro/55006e4fa33311926f5110e3/ kepemimpinan-transformatif

10. Haryono N. Jejaring Untuk Membangun Kolaborasi Sektor Publik. J Jejaring Adm Publik. 2012;4(1):47-53.

11. Aris Febri Rahmanto. Peranan Komunikasi Dalam Organisasi. J Komunikologi. 2004;1(2):59-75.

12. Herawati E. Komunikasi dalam Era Teknologi Komunikasi Informasi. Humaniora. 2017;2(1):100-9. 